\title{
PENGARUH KEPUASAN KERJA, MOTIVASI, DAN PERSEPSI ATAS DUKUNGAN ORGANISASIONAL TERHADAP KOMITMEN ORGANISASI GURU TAMAN KANAK- KANAK DI KECAMATAN SANDEN, KABUPATEN BANTUL, YOGYAKARTA
}

\author{
Agustin Eka Nurhayati \\ Fakultas Ekonomi Universitas Sarjanawiyata Tamansiswa
}

\begin{abstract}
The objective of this study was to explore the influence of job satisfaction, motivation and perceived organizational support on organizational commitment of kindergarten teachers in Sanden, Bantul, Yogyakarta.This research used quantitative approach with survey method in which questionnaire was used to gather the data. The main data of this research were gained from 85 respondents.

In this research, multiple regression was used to analyze the data to know the influence of job satisfaction, motivation, and perceived organizational support on organizational commitment. The multiple regression model $Y=0,401 X_{1}+0,332 X_{2}+0,099 X_{3}$, showed that the job satisfaction influenced positively on organizational commitmentof kindergarten teachers (0,401). Motivation also influenced positively on organizational commitmentof kindergarten teachers (0,332). It was also found that perceived organizational support not influenced positively on organizational commitment $(0,099)$.
\end{abstract}

Key words: job satisfaction, motivation, perceived organizational support, organizational commitment.

\section{PENDAHULUAN}

Menjadi guru baik itu guru untuk anak usia dini (AUD), guru Taman Kanak-kanak (TK), guru Sekolah Dasar (SD), guru Sekolah Menengah bahkan guru mahasiswa (dosen) adalah pekerjaan yang mulia, sebab dari gurulah segala peradaban dimulai dan mengalami perkembanganyang sangat mengagumkan hingga saat ini. Tentu saja hal ini dapat terjadi selain dari peran guru juga karena dukungan dari orang tua. Orang tua sebagai guru pertama dan utama bagi anak, karena pendidikan yang pertama didapatkan oleh anak adalah pendidikan nonformal yaitu di lingkungan keluarganya sendiri. Sedangkan pendidikan formal yang diterima oleh anak yang pertama yaitu di tingkat sekolah Taman Kanak-kanak (TK). Hal ini menunjukkan bahwa peran guru TK sangatlah penting untuk menanamkan konsep dasar belajar pada anak, membentuk karakter dan kecerdasan anak.

Seiring dengan perkembangan zaman yang semakin pesat, menuntut adanya peningkatan profesionalisme pada diri guru TK, termasuk guru TK di Kecamatan Sanden yang berjumlah 110 orang yang tersebar di 26 TK. Oleh karena itu, profesi guru TK tentu harus direkonstruksi dan direka ulang agar tidak seperti yang sekarang ini tengah terjadi, karena guru memegang peranan penting dalam proses belajar mengajar dan guru merupakan sumber daya manusia yang sangat penting untuk kemajuan sekolah. Selain profesionalisme, komitmen seorang guru TK harus kuat.

Fenomena yang terjadi saat ini banyak guru TK di Kecamatan Sanden yang dengan mudah meninggalkan TK seakan kurang peduli dengan kemajuan TK. Mengingat bahwa kemajuan TK tergantung pada komitmen guru tersebut maka muncul pertanyaan bagaimana komitmen guru TK di Kecamatan Sanden terhadap sekolahnya.

\section{Perumusan Masalah}

Masalah yang akan dipecahkan dalam penelitian ini adalah:

1. Apakah kepuasan kerja mempengaruhi komitmen organisasi guru TK di Kecamatan Sanden, Kabupaten Bantul, Yogyakarta? 
2. Apakah motivasi mempengaruhi komitmen organisasi guru TK di Kecamatan Sanden, Kabupaten Bantul, Yogyakarta?

3. Apakah persepsi atas dukungan organisasional mempengaruhi komitmen organisasi guru TK di Kecamatan Sanden, Kabupaten Bantul, Yogyakarta?

\section{Tujuan Penelitian}

Penelitian ini bertujuan untuk:

1. Mengetahui pengaruh kepuasan kerja terhadap komitmen organisasi guru TK di Kecamatan Sanden, Bantul, Yogyakarta

2. Mengetahui pengaruh motivasi terhadap komitmen organisasi guru TK di Kecamatan Sanden, Bantul, Yogyakarta

3. Mengetahui pengaruh persepsi atas dukungan organisasional terhadap komitmen organisasi guru TK di Kecamatan Sanden, Bantul, Yogyakarta.

\section{KERANGKA TEORITIS}

\section{Komitmen Organisasi}

Menurut Robbins (2010:75) komitmen organisasi adalah suatu keadaan dimana pekerja memihak pada suatu organisasi tertentu dan tujuan-tujuannya, serta berniat untuk mempertahankan keanggotaan dalam organisasi tersebut. Hampir sama dengan Robbins (2010), Greenberg dan Baron (2003) dalam Christiono (2007) menyebutkan bahwa komitmen organisasi menggambarkan seberapa jauh seseorang itu mengidentifikasikan dan melibatkan dirinya pada organisasinya dan keinginan untuk tetap tinggal di organisasi tersebut. Dalam konteks organisasional, fenomena ini mengacu pada level komitmen karyawan terhadap organisasi yang mempunyai hubungan yang sangat erat dengan sikap dan perilaku mereka di tempat kerja (Amiri, et al. 2013).

Mowday, Porter, dan Steers (1982) dalam Tella, et al. (2007), Amiri, et al. (2013) mempercayai komitmen organisasional sebagai sebuah struktur multidimensioanl yang ditentukan berdasarkan tekanan pada perasaan identitas yang dihubungkan dengan pekerjaan dengan tiga faktor: 1) mempercayai dan menerima tujuan dan nilai organisasi, 2) selalu menunjukkan usaha yang sungguh-sungguh untuk kepentingan organisasi, dan 3) kecenderungan yang kuat untuk bertahan dalam organisasi. Untuk itu, komitmen organisasional yang tinggi diperoleh berdasarkan kepercayaan yang kuat untuk menerima nilai dan tujuan organisasi, berusaha sungguh-sungguh untuk menjalankan tugas organisasi, dan kecenderungan yang kuat untuk bertahan di organisasi.

Untuk memahami komitmen lebih mendalam, Meyer dan Allen (1991) dalam Tella, et al. (2007) dan Puspitasari (2011) membagi komitmen ke dalam tiga komponen. Ketiga komponen tersebut yaitu:

1) Komitmen Afektif (affective commitment), yaitu komitmen sebagai keterikatan afektif atau psikologis karyawan terhadap pekerjaannya. Komitmen afektif berkaitan erat dengan keterikatan emosional, pengenalan, dan keterlibatan karyawan dalam pekerjaannya sebagai sesuatu yang menyenangkan dan membuatnya nyaman untuk menjadi anggota organisasi.

2) Komitmen Ekonomis (continuance commitment), mengarah kepada perhitungan untung-rugi dalam diri karyawan sehubungan dengan keinginannya untuk tetap berpertahan atau meninggalkan pekerjaannya. Artinya, komitmen di sini dianggap sebagai persepsi harga yang harus dibayar jika ia meninggalkan pekerjaan tersebut. Komitmen ini menyebabkan karyawan bertahan pada suatu pekerjaan karena ia membutuhkan.

3) Komitmen Normatif (normative commitment), yaitu komitmen sebagai kewajiban untuk bertahan dalam pekerjaan. Komitmen ini menyebabkan karyawan bertahan pada suatu pekerjaan karena mereka wajib melakukannya.

\section{Kepuasan Kerja}

Menurut Hani Handoko (2001:193) kepuasan kerja (job satisfaction) adalah keadaan emosional yang menyenangkan atau tidak menyenangkan dengan mana para karyawan memandang pekerjaan mereka. Locke dan Lathan (1976) dalam Tella, et al. (2007) memberikan definisi yang luas tentang kepuasan kerja, yaitu sebagai sesuatu yang menyenangkan atau keadaan emosional yang 
positif dari penilaian suatu pekerjaan atau dari pengalaman kerja. Kepuasan kerja mencerminkan perasaan seseorang terhadap pekerjaannya. Ini nampak dalam sikap-sikap positif karyawan terhadap pekerjaan dan segala sesuatu yang dihadapi di lingkungan kerjanya. Sikap senang dan tidak senang terhadap pekerjaan dan lingkungan pekerjaan akan tercermin dari perilakunya dalam melaksanakan pekerjaan.

Kepuasan kerja juga dapat diartikan sebagai suatu efektivitas atau respon emosional terhadap berbagai aspek pekerjaan (Kreitner dan Kinicki, 2005:271) seperti halnya sikap dan persepsi sebagai konsekuensi dari pengaruh tingkat kecocokan antara individu dengan organisasi (Ivancevich \& Matteson 2002; Spector 1997 dalam Lumley et al. 2011). Devinisi ini berarti bahwa kepuasan kerja bukanlah suatu konsep tunggal. Sebaliknya, seseorang dapat relatif puas dengan suatu aspek dari pekerjaannya dan tidak puas dengan salah satu atau lebih aspek yang lainnya. Penyebab dari kepuasan kerja adalah pemenuhan, ketidakcocokan, pencapaian nilai, persamaan, dan komponen watak/genetik.

Menurut Carrell, Jenings, dan Heavrin (1997) dalam Sugiarti (2001) terdapat tiga pendekatan yang digunakan untuk menggambarkan kepuasan kerja:

\section{1) Herzberg's Two-factor Theory}

Herzberg menemukan bahwa faktorfaktor yang menyebabkan kepuasan kerja dan ketidakpuasan kerja berbeda. Kepuasan kerja terdiri dari beberapa faktor yang dihubungkan dengan pekerjaan itu sendiri, seperti kesempatan promosi, kesempatan untuk pertumbuhan pribadi, penghargaan, tanggung jawab dan pencapaian (achievement). Ia menyebutnya sebagai motivator karena faktor tersebut berhubungan dengan tingkat kepuasan yang tinggi. Sedangkan ketidakpuasan kerja berhubungan dengan kondisi sekeliling pekerjaan yaitu kualitas supervisi, upah, peraturan perusahaan, kondisi fisik pekerjaan, hubungan dengan rekan kerja dan keselamatan kerja.

\section{2) Locke's Value Theory}

Locke mengklaim bahwa kepuasan kerja terjadi ketika reward yang diterima individu sesuai dengan outcomes yang diinginkan. Menurut Locke kepuasan kerja didasarkan pada ketidaksesuaian yang ada antara apa yang orang miliki dan apa yang orang inginkan pada berbagai aspekpekerjaan mereka. Semakin kecil ketidaksesuaian semakin puas mereka dengan pekerjaannya.

\section{3) Moorhead and Griffin's causes and consequences}

Moorhead dan Griffits berpendapat bahwa penyebab utama dari kepuasan atau ketidakpuasan kerja dikategorikan menjadi tiga kategori: (1) faktor organisasional (penggajian, kesempatan promosi, pekerjaan itu sendiri, kebijaksanaan dan prosedur, kondisi pekerjaan), (2) faktor kelompok (rekan kerja, supervisi), (3) personal factor (kebutuhan, aspirasi dan instrumental benefit).

\section{Motivasi}

Motivasi merupakan proses dasar psikologis manusia (Mine, Ebrahimi \& Wache, 1995 dalam Tella, et al. 2007), yang dihasilkan dari penimbulan, bimbingan, dan kegigihan dari tindakan sukarela untuk mencapai tujuan organisasi dan tujuan pribadi (Pool dan Pool, 2007 dalam Altindis, 2011). Luthans (1998) dalam Tella, et al. (2007) menyatakan bahwa motivasi adalah sebuah proses yang membangunkan, menguatkan, dan menopang perilaku serta perbuatan. Memotivasi merupakan proses mengatur pengaruh perilaku yang didasarkan pada pengetahuan apa yang membuat manusia ditandai. Dapat dikatakan bahwa motivasi merupakan suatu proses untuk merangsang seseorang melakukan sesuatu dan mencapai apa yang diinginkan.

Mitchell (1982) dalam Kreitner dan Kinicki (2005:248) mendefinisikan motivasi sebagai proses-proses psikologis meminta arahan, dan menetapkan tindakan sukarela yang mengarah pada tujuan.

Ada beberapa teori motivasi yang terkenal, antara lain teori dari Abraham Maslow yang dikenal dengan sebutan teori kebutuhan, yang digambarkan dalam suatu hirarki. Hirarki tersebut membagi kebutuhan ke dalam lima kategori yaitu (1) kebutuhan fisiologis; (2) kebutuhan rasa aman; (3) kebutuhan sosial, keinginan untuk dicintai dan mencintai, 
termasuk kasih sayang, pengakuan sebagai anggota masyarakat dan persahabatan; (4) kebutuhan akan harga diri/ penghargaan, kebutuhan akan reputasi dan pengakuan dari orang lain, seperti percaya diri, status sosial, jabatan, wewenang, dan perhatian; (5) kebutuhan aktualisasi diri, keinginan untuk pemenuhan diri untuk menjadi yang terbaik dari apa yang mampu dilakukan, (Maslow, 1954 dalam Robbins, 2010:87).

Selain teori Maslow, teori motivasi yang lain yaitu teori harapan (expectancy theory). Teori yang diungkapkan oleh Greenberg (1999) dalam Murti, et al. (2012) memandang motivasi sebagai akibat dari tiga tipe keyakinan yang dimiliki individu, terdiri dari ekspektasi berupa keyakinan bahwa usaha seseorang akan mempengaruhi performance.

Selain teori tersebut, masih ada teori motivasi lain yaitu teori dari McClelland (1986) dalam Robbins (2010:90) yang fokus ke tiga kebutuhan: (1) kebutuhan akan prestasi (need for achievement atau lebih dikenal dengan nAch); (2) kebutuhan akan kekuasaan (need for power atau disingkat nPow); dan (3) kebutuhan akan keanggotaan/ afiliasi (need for affiliation atau disingkat $n A f f)$.

\section{Persepsi Dukungan Organisasional (Perceived Organizational Support/ POS)}

Menurut Robbins (2010:56) persepsi merupakan sebuah proses yang mana individu mengatur dan menafsirkan kesan-kesan dengan indera mereka dengan tujuan untuk menunjukkan maksud pada lingkungan mereka.Kreitner dan Kinicki (2005:208) mendefinisikan persepsi sebagai proses kognitif yang memungkinkan kita dapat menafsirkan dan memahami lingkungan sekitar kita. Dengan kata lain, persepsi merupakan proses interprestasi seseorang akan lingkungannya.

Masih dalam literatur yang sama, Robbins (2010:76) menyebutkan persepsi terhadap dukungan organisasi atau lebih terkenal dengan perceived organizational support (POS) adalah derajad sejauh mana pekerja percaya bahwa organisasi menghargai kontribusi mereka dan memperhatikan kesejahteraan mereka.Einsenberger, Huntington, dan Sowa (1986) dalam LaMastro (1999), O’Driscoll (1999), Gokul (2012) menunjukkan bahwa individu cenderung untuk mempercayai bahwa organisasi menilai kontribusi mereka, dan peduli akan kesejahteraan mereka.

Sebagian orang mungkin mempunyai perasaan bahwa organisasi mendukung mereka. Perasaan tersebut muncul karena beberapa faktor, seperti kesediaan anggota organisasi yang lain untuk membantu mereka, adanya teman kerja yang mendampingi, adanya peralatan khusus yang disediakan organisasi agar pekerjaan yang dikerjakan dapat segera selesai. Perasaan yang kuat dari POS juga muncul dengan adanya kesempatan yang diberikan oleh organisasi agar karyawan mengikuti pelatihan di bidang khusus atau di bidang yang diminati (Eisenberger, Cummings, Armeli, \& Lynch, 1997 dalam LaMastro, 1999).

\section{MODEL PENELITIAN}

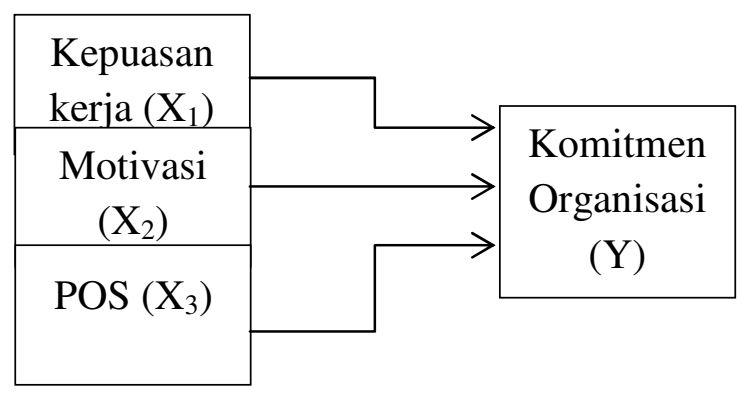

Gambar. 1. Kerangka Konseptual Penelitian HIPOTESIS

Hipotesis dalam penelitian ini adalah:

1. Ada pengaruh yang signifikan antara kepuasan kerja dengan komitmen organisasi

2. Ada pengaruh yang signifikan antara motivasi dengan komitmen organisasi

3. Ada pengaruh yang signifikan antara POS dengan komitmen organisasi

\section{METODE PENELITIAN \\ Sifat Penelitian}

Penelitian ini bersifat kuantitatif dengan metode survei sebagai metode penelitian. Metode pengumpulan data dengan menggunakan kuesioner.

\section{Populasi dan Sampel}


Populasi dalam penelitian ini adalah 110 guru TK di Sanden dengan sampel sejumlah 85 guru.

\section{Karakteristik Responden}

Tabel.1

Klasifikasi responden berdasarkan lama bekerja

\begin{tabular}{|c|c|c|c|c|c|}
\hline \multicolumn{6}{|c|}{ LamaKerja } \\
\hline & & Frequency & Percent & Valid Percent & $\begin{array}{c}\text { Cumulative } \\
\text { Percent }\end{array}$ \\
\hline Valid & $1 \mathrm{TH}$ & 2 & 2.4 & 2.4 & 2.4 \\
\hline & $10 \mathrm{TH}$ & 8 & 9.4 & 9.4 & 11.8 \\
\hline & $11 \mathrm{TH}$ & 4 & 4.7 & 4.7 & 16.5 \\
\hline & $12 \mathrm{TH}$ & 7 & 8.2 & 8.2 & 24.7 \\
\hline & $13 \mathrm{TH}$ & 2 & 2.4 & 2.4 & 27.1 \\
\hline & $15 \mathrm{TH}$ & 5 & 5.9 & 5.9 & 32.9 \\
\hline & $16 \mathrm{TH}$ & 1 & 1.2 & 1.2 & 34.1 \\
\hline & $17 \mathrm{TH}$ & 3 & 3.5 & 3.5 & 37.6 \\
\hline & $20 \mathrm{TH}$ & 2 & 2.4 & 2.4 & 40.0 \\
\hline & $22 \mathrm{TH}$ & 1 & 1.2 & 1.2 & 41.2 \\
\hline & $23 \mathrm{TH}$ & 1 & 1.2 & 1.2 & 42.4 \\
\hline & $25 \mathrm{TH}$ & 2 & 2.4 & 2.4 & 44.7 \\
\hline & $26 \mathrm{TH}$ & 2 & 2.4 & 2.4 & 47.1 \\
\hline & $27 \mathrm{TH}$ & 5 & 5.9 & 5.9 & 52.9 \\
\hline & $28 \mathrm{TH}$ & 4 & 4.7 & 4.7 & 57.6 \\
\hline & $3 \mathrm{TH}$ & 2 & 2.4 & 2.4 & 60.0 \\
\hline & $30 \mathrm{TH}$ & 8 & 9.4 & 9.4 & 69.4 \\
\hline & $31 \mathrm{TH}$ & 3 & 3.5 & 3.5 & 72.9 \\
\hline & $32 \mathrm{TH}$ & 1 & 1.2 & 1.2 & 74.1 \\
\hline & $4 \mathrm{TH}$ & 1 & 1.2 & 1.2 & 75.3 \\
\hline & $5 \mathrm{TH}$ & 4 & 4.7 & 4.7 & 80.0 \\
\hline & $6 \mathrm{TH}$ & 4 & 4.7 & 4.7 & 84.7 \\
\hline & $7 \mathrm{TH}$ & 5 & 5.9 & 5.9 & 90.6 \\
\hline & $8 \mathrm{TH}$ & 3 & 3.5 & 3.5 & 94.1 \\
\hline & $9 \mathrm{TH}$ & 5 & 5.9 & 5.9 & 100.0 \\
\hline & Total & 85 & 100.0 & 100.0 & \\
\hline
\end{tabular}

Tabel.2

Klasifikasi responden berdasarkan penghasilan

\begin{tabular}{|c|c|c|c|c|c|}
\hline \multicolumn{6}{|c|}{ Penghasilan } \\
\hline & & Frequency & Percent & Valid Percent & $\begin{array}{c}\text { Cumulative } \\
\text { Percent }\end{array}$ \\
\hline \multirow[t]{6}{*}{ Valid } & $<1 \mathrm{JT}$ & 52 & 61.2 & 61.2 & 61.2 \\
\hline & $>4 \mathrm{JT}$ & 12 & 14.1 & 14.1 & 75.3 \\
\hline & $1-2 \mathrm{JT}$ & 5 & 5.9 & 5.9 & 81.2 \\
\hline & $2.1-3 \mathrm{JT}$ & 2 & 2.4 & 2.4 & 83.5 \\
\hline & 3.1-4 JT & 14 & 16.5 & 16.5 & 100.0 \\
\hline & Total & 85 & 100.0 & 100.0 & \\
\hline
\end{tabular}

Tabel.3

Klasifikasi responden berdasarkan status

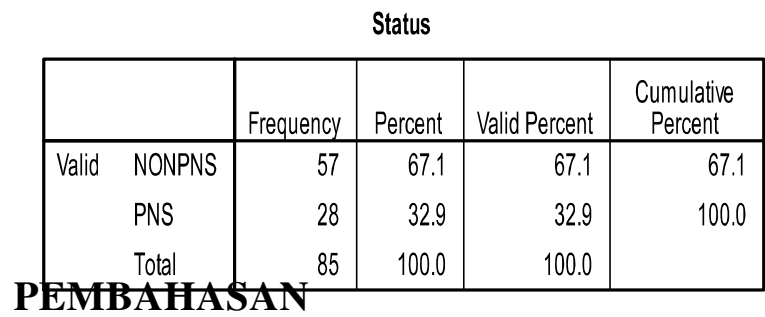

Tabel.4

Hasil Regresi Berganda

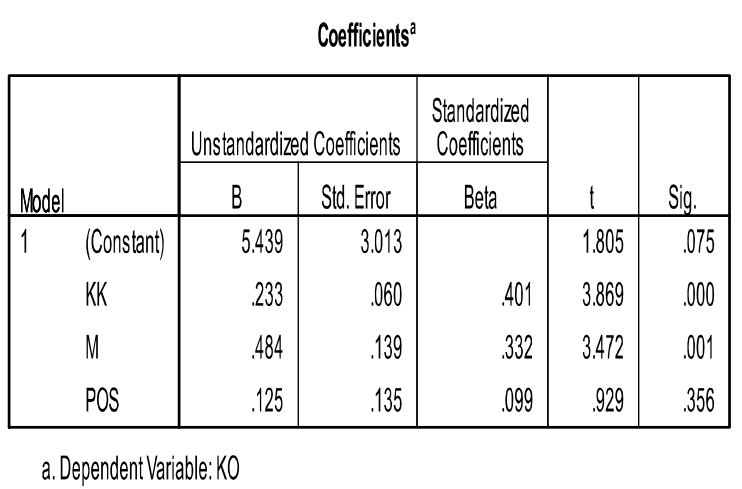

Tabel.5

Model Regresi Berganda

Model Summary

\begin{tabular}{|c|c|r|r|r|}
\hline Model & R & R Square & \multicolumn{1}{c|}{$\begin{array}{c}\text { Adjusted R } \\
\text { Square }\end{array}$} & $\begin{array}{c}\text { Std. Error of } \\
\text { the Estimate }\end{array}$ \\
\hline 1 & $.702^{\mathrm{a}}$ & .493 & .474 & 3.138 \\
\hline
\end{tabular}

a. Predictors: (Constant), POS, M, KK

Hasil regresi berganda menunjukkan bahwa variabel bebas hanya mempengaruhi variabel terikatnya sebesar 0,474 atau $47,4 \%$. Hal ini menunjukkan bahwa ada $52,6 \%$ faktor lain yang dapat mempengaruhi komitmen organisasi guru TK di Sanden. Selain itu, dengan melihat tabel Coefficients kita dapat mengetahui hasil regresi berganda dalam bentuk persamaan yaitu $\mathrm{Y}=0,401 \mathrm{X}_{1}+0,332 \mathrm{X}_{2}+$ $0,099 X_{3}$ yang berarti bahwa variabel $X 1$ (kepuasan kerja) mempengaruhi Y (komitmen organisasi) sebesar 0,401, variabel X2 (motivasi) mempengaruhi Y sebesar 0,332, dan variabel X3 (POS) mempengaruhi $\mathrm{Y}$ sebesar 0,099 .

Hasil pengujian hipotesis 1 menunjukkan bahwa kepuasan kerja berpengaruh secara positif terhadap komitmen organisasi $(0,401$ dengan tingkat sinifikansi $0,000)$.Hasil pengujian hipotesis 2 , motivasi berpengaruh secara positif terhadap komitmen organisasi $(0,332$ dengan signifikansi $0,001)$.Hasil pengujian hipotesis 3 menunjukkan 
bahwa POS tidak berpengaruh secara positif terhadap komitmen organisasi (0,099 dengan signifikansi 0,356).

\section{KESIMPULAN DAN SARAN}

Kesimpulan

Dari hasil penelitian ini dapat disimpulkan bahwa kepuasan kerja dan motivasi berpengaruh secara signifikan terhadap komitmen organisasi sedangkan POS tidak berpengaruh secara signifikan. Hal ini berarti bahwa semakin tinggi kepuasan kerja dan motivasi maka semakin tinggi pula komitmen sedangkan semakin tinggi POS belum tentu komitmen juga tinggi.

\section{Saran} memberikan saran:

Dalam penelitian ini penulis

1. Sekolah (TK) diharapkan mampu memberikan motivasi yang tinggi terhadap guru karena motivasi akan meningkatkan kepuasan kerja dan kepuasan kerja meningkatkan komitmen.

2. TK diharapkan mampu memberikan dukungan yang besar kepada guru, tentu saja sesuai dengan kemampuan TK tersebut. Hal ini bertujuan agar POS dapat meningkatkan komitmen.

\section{DAFTAR PUSTAKA}

Altindis, Selma. (2011). "Job Motivation and Organizational Commitment Among The Health Professionals: A questionaire Survey", African Journal of Business Management, Vol. 5, No. 21, pp. 8601-8609.

Amiri, H., Mirhashemi, M., and Parsamoein, K. (2013). "The Prediction of Employees' Organizational Commitment Based on Their Perception of Job Characteristics and Job Roles", Journal of Behavioral Sciences in Asia, Vol. 1 (2), pp. 50-63.

Christiono, Suswan. (2007). Pengaruh Komitmen Organisasi, Job Insecurity Dan Kepuasan Kerja Terhadap Intensi Turnover: Studi di PT Panji Dananjaya. Skripsi, Tidak Dipublikasikan, Fakultas Ekonomika dan Bisnis Universitas Gadjah Mada.

Gokul, A., Sridevi, G., and Srinivasan, P.T. (2012). "The Relationship Between
Perceived Organizational Support, Work Engagement and Affective Commitment", AMET International Journal of Management, pp. 29-37.

Handoko, T. Hani. (2001). Manajemen Personalia Dan Sumber Daya Manusia. Yogyakarta: BPFE Yogyakarta.

Kreitner, Robert dan Angelo Kinicki. (2005). Organizational Behavior. (Terjemahan), Edisi 5, Jilid 1. Jakarta: Salemba Empat.

$$
\text { LaMastro, Valerie. }
$$

"Commitment and Perceived Organizational Support", National Forum of Applied Educational Research Journal, Vol. 12, No. 3, pp. 1-13.

Lumley, E.J; M. Coetzee; R. Tladinyane and N. Ferreira. (2011). "Exploring the Job Satisfaction and Organizational Commitment Of Employees in the Information Technology Environment", Southern African Business Review, Vol. 15, No. 1, pp. 100-118.

Murty, Windy Aprilia dan Gunasti Hudiwinarsih. (2012). "Pengaruh Kompensasi, Motivasi, dan Komitmen Organisasional Terhadap Kinerja Karyawan Bagian Akuntansi: Studi Kasus pada Perusahaan Manufaktur di Surabaya", The Indonesian Accounting Review, Vol. 2, No. 2, pp. 215-228.

O'Driscoll, Michael P., and Randall, Donna M. (1999). "Perceived Organizational Support, Satisfaction with Rewards, and Employee Job Imvolvement and Organizational Commitment", International Association of Applied Psychology: An International Review, Vol. 48, No. 2, pp. 197-209.

Puspitasari, Dewi dan Setia Asyanti. (2011). "Faktor yang Paling Berpengaruh Terhadap Komitmen Kerja Perawat Panti Wreda Di Surakarta", Jurnal Psikologi Universitas Diponegoro, Vol. 9, No. 1, h. 57-65.

Robbins, Stephen P., and Timothy A. Judge. (2010). Essentials Of Organizational Behavior, $10^{\text {th }}$ Edition. New Jersey: Pearson Education, Inc. 
Sugiarti. (2001). Analisis Rasional Faktor Stres Kerja Terhadap Kepuasan Kerja Dan Keinginan Untuk Meninggalkan Pekerjaan, Studi pada Pemerintah Daerah Kabupaten Sukoharjo. Tesis, Tidak Dipublikasikan, Fakultas Ekonomika dan Bisnis Universitas Gadjah Mada. 